\title{
Lantana trifolia: Phytochemical and elemental composition, proximate contents and gas chromatography-mass spectrometry profile
}

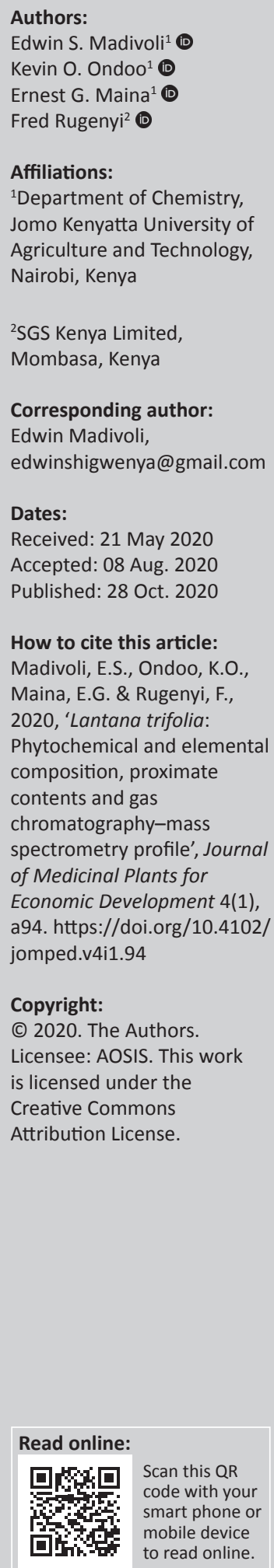

Background: With increasing concern over food insecurity, there is the need to incorporate wild edible plants in our meals as they can provide adequate level of nutrition when consumed as food.

Aim: The objective of this study was to evaluate the proximate composition, elemental composition, total phenolic content, total flavonoid content and gas chromatography-mass spectrometry (GC-MS) profile of Lantana trifolia.

Setting: This study was carried out in Juja, Kenya where the samples were collected, prepared and stored at the Department of Chemistry, Jomo Kenyatta University of Agriculture and Technology.

Methods: The proximate and elemental compositions of the leaves, stalk and root samples were evaluated by using standard procedures, whilst the total phenolic and flavonoid contents were evaluated by using Folin-Ciocalteu and aluminium chloride method. The secondary metabolites present in the crude methanolic extracts of the whole plant were determined by using GC-MS.

Results: The proximate and elemental analyses of the plant revealed that L. trifolia can be a good source of essential elements, proteins, crude fibre and carbohydrates. The protein, fat, crude fibre and carbohydrate contents in the leaves were found to be higher compared with the stalks and roots, whilst the ash and moisture contents were found to be higher in the roots. The concentrations of calcium, iron, magnesium and zinc in the leaves were found to be $8860.75 \pm 565.27,11003.10 \pm 143.24,1520.25 \pm 26.85$ and $39.66 \pm 15.68 \mathrm{mg} / \mathrm{kg}$, respectively, compared with the roots and stalks, which were lower.

Conclusion: The concentration of total phenolic and total flavonoid compounds and GC-MS profile of the methanolic extracts revealed that L. trifolia can be a good source of secondary metabolites, some of which have reported to be free radical scavengers. Hence, L. trifolia can not only be used as a source of important secondary metabolites, but its nutritional content suggests that the plant can be used to combat nutrient deficiency amongst many communities who lack adequate resources, because it thrives in the wild.

Keywords: Lantana trifolia; GC-MS; proximate analysis; elemental composition.

\section{Introduction}

Wild medicinal plants have traditionally been used for their medicinal and nutriment values. Crude extracts from aromatic and medicinal plants have attracted scientists' attention because of their ability to prepare alternative traditional medicine and food additives (Hossain et al. 2013). About three quarters of the world depend on traditional medicine for the management of their healthcare. It is evident that several plants have been found useful as traditional Ayurvedic medicine for the treatment and management of distinct inflammatory disorders and for wound management. Dietary polyphenols have been reported to inhibit arachidonic acid peroxidation and they also possess cyclooxygenase (COX-2) inhibitory or stimulatory effects (Shaikh, Pund \& Gacche 2016). Secondary metabolites such as phenolic compounds have been reported as promising tools in eliminating the causes and effects of skin ageing, skin diseases and skin damage, including wounds and burns, because they are of plant origin and have low toxicity (Dzialo et al. 2016; Scheller et al. 2011; Wang et al. 2014a; Witte \& Barbul 2002). Moreover, there has been increasing concern about the rate of malnutrition during pregnancy and early childhood in Kenya and the world because malnutrition has many adverse effects as it hinders normal child development and long-term well-being of any given society (USAID 2018). With the ever 
persistent droughts in Kenya as a result of climate change (Tumushabe 2018), high global food prices (Schmidhuber \& Tubiello 2007), high costs of food production (Peduzzi \& Harding Rohr Reis 2012), low purchasing power and displacement of farmers every election year, the country faces severe food insecurity. In 2017, this resulted in an estimated 3.4 million people suffering from acute food insecurity (USAID 2018). Numerous types of wild edible plants (WEPs) have been exploited in developing countries as a means or source of food as they can provide the adequate level of micro- and macronutrients needed to fight nutrition deficiency (Bharucha \& Pretty 2010). For instance, Adansonia digitata, Tamarindus indica, Sclerocarya birrea and Uapaca kirkiana have been used to produce juices and local alcoholic drinks in Tanzania (Ruffo, Birnie \& Tengnas 2002).

Although only a few wild food plants have been analysed for their nutritional content, the little available data indicate that many local vegetables and fruits have higher nutritive value than the exotic vegetables commonly sold in the markets (Horton \& Mannar 2018; Ruffo et al. 2002). Lantana trifolia L. or lantana, as it is commonly referred to, is a highly invasive shrub thought to have been brought into Africa from Europe. This plant is usually harvested from the wild for its medicinal value, where it is used locally as a source of food, medicine and wood. As a source of medicine, L. trifolia has been reported to have anti-inflammatory and antinociceptive activities by preventing prostaglandins from being produced, thereby eliminating or reducing pain (Silva et al. 2005; Waweru, Osuwat \& Wambugu 2017). In the East African countries of Kenya, Tanzania and Uganda, the plant is commonly used in the treatment of coughs and colds, in the preparation of ethnoveterinary remedies and in the management of respiratory symptoms and diarrhoea. Its leaves are used not only to treat asthma, chronic rhinitis, menstrual pains, eye infections, fever amongst other ailments but also as animal fodder, whilst the fruits are normally eaten to quench thirst (Ruffo et al. 2002). Even though its medicinal value has been widely reported, there is little information regarding its nutritional content and the role it plays in enriching the food basket. The plant has been reported to contain monoterpenes, sesquiterpenes, triterpenoids, flavonoids, phenylethanoid glycosides, steroids, iridoid glycosides and furanonaphthoquinones. The common major constituents identified in the oils are the sesquiterpenes, caryophyllene, $\beta$-caryophyllene, E and Z-caryophyllene, iso-caryophyllene, caryophyllene oxide, caryophylleneepoxide, germacrene Dand bicyclogermacrene (Sousa \& Costa 2012). The purpose of this study was to evaluate the phytochemical composition, proximate content, macro- and micronutrient contents and the secondary metabolites present in L. trifolia. The proximate, micro- and macronutrient contents of the leaves, stalk and root samples were evaluated by using the standard procedures, whilst the total phenolic and flavonoid contents were evaluated by using Folin-Ciocalteu and aluminium chloride method. The secondary metabolites present in the crude methanolic extracts of the whole plant were determined by using gas chromatography-mass spectrometry (GC-MS).

\section{Materials and methods Collection and sample preparation}

The samples were collected from Juja, Thika County in Kenya, based on the ethnopharmacological use through interviews with traditional medicine practitioners in the area. Botanical identity of the plants was achieved by a botanist from the Department of Botany, Jomo Kenyatta University of Agriculture and Technology, Kenya. The samples were then chopped into small pieces after thoroughly washing in running water and air-dried on the laboratory bench at room temperature for 4 weeks. The dried plant samples were ground into a fine powder by using an in-house mechanical mill (Madivoli et al. 2018; Maina et al. 2019).

\section{Estimation of micro- and macronutrient contents of Lantana trifolia}

The micro- and macronutrient contents of L. trifolia were assayed and analysed by using an Agilent 720 ICP-OES. One gram of the ground sample was weighed into $50 \mathrm{~mL}$ porcelain crucibles and placed in a cool muffle furnace whose temperature was gradually increased until a temperature of $550{ }^{\circ} \mathrm{C}$ was attained. The samples were ashed for 5 hours and then cooled, and the ash was dissolved in $5 \mathrm{~mL}$ portions of $2 \mathrm{~N} \mathrm{HCl}$ and mixed with a glass rod. It was filtered by using Whatman Filter Paper No. 42 into $50 \mathrm{~mL}$ volumetric flask and finally topped to the mark with deionised water to await analysis (Estefan, Sommer \& Ryan 2013). An Agilent 720 ICP-OES was used for the analysis of trace and other elements, and a Windows 7 compatible software provided by Agilent $^{\odot}$ was used to process the spectral data and compare the light intensities measured at various wavelengths for standard solutions with intensities from the sample solutions (Maina et al. 2019).

\section{Proximate analysis}

For proximate analysis, the plant was separated into leaves, stalks and root and ground into powder by using a mechanical milling machine (locally assembled, no model number). The powdered samples were then analysed for moisture, protein, fat and ash contents by using methods adopted from the literature, and the carbohydrate content was determined as follows: $(100-[\%$ moisture $+\%$ protein $+\%$ fat $+\%$ ash]) (Maina et al. 2019; Olaniyi, Lawal \& Olaniyi 2018; Thangaraj 2016).

\section{Extraction of plant material}

To obtain the crude extract, cold extraction was achieved by using methanol as the extracting solvents. The extraction was carried out by weighing $100 \mathrm{~g}$ of the fine powders of the whole plant sample and macerating in $1000 \mathrm{~mL}$ methanol. The extracts were filtered by using Whatman Filter Paper No. 1 
(Whatman international, England) and concentrated by using a Rota evaporator (BUCHI R 200) at $40{ }^{\circ} \mathrm{C}$. The crude extracts were then left to dry in the fume chamber, after which they were stored at $4{ }^{\circ} \mathrm{C}$ for further analysis (Madivoli et al. 2018).

\section{Quantification of total phenols}

The total phenolic content of crude methanolic extract of L. trifolia was determined by using colorimetric method with the reagent Folin-Ciocalteu (Lefahal et al. 2018; Thangaraj 2016). A volume of $300 \mu \mathrm{L}$ of extract solution $(1 \mathrm{mg} / \mathrm{mL}$ in methanol) was mixed with $1500 \mu \mathrm{L}$ of Folin-Ciocalteu reagent (diluted 10-fold). After $4 \mathrm{~min}, 1200 \mu \mathrm{L}$ of $\mathrm{Na}_{2} \mathrm{CO}_{3}(75 \mathrm{~g} / \mathrm{L}$ ) was added. The mixture was incubated at room temperature in the dark for $2 \mathrm{~h}$, and the absorbance of the reaction mixture was measured at $765 \mathrm{~nm}$ by using Ultra-violet visible spectrophotometer (UV/VIS) spectrophotometer. Gallic acid was used as a standard for calibration curve, and the results were expressed as gallic acid equivalents $(\mu \mathrm{g} \mathrm{GAE} / \mathrm{mg}$ ) (Lefahal et al. 2018).

\section{Quantification of total flavonoids}

Total flavonoid content of the methanolic extract was performed by colorimetric method using aluminium chloride (Lefahal et al. 2018; Thangaraj 2016). A volume of $1 \mathrm{~mL}$ of $2 \%$ $\mathrm{AlCl}_{3}$ methanol solution was mixed with $1 \mathrm{~mL}$ of sample solution $(1 \mathrm{mg} / \mathrm{mL})$. The absorbance was measured at $415 \mathrm{~nm}$ by using UV/VIS spectrophotometer After incubation for $10 \mathrm{~min}$ at room temperature, quercetin was used as a standard for calibration curve, and the results were expressed as quercetin equivalents ( $\mu \mathrm{g} \mathrm{QE} / \mathrm{mg}$ ) (Lefahal et al. 2018).

\section{Gas chromatography-mass spectrometry profile of Lantana trifolia}

Gas chromatography-mass spectrometry analysis of crude methanol extracts was evaluated by using a Shimadzu GC-MS QP2010SE. In brief, $1 \mathrm{~g}$ of the powdered plant samples was sequentially extracted with $10 \mathrm{~mL}$ hexane followed by methanol before GC-MS analysis. A Shimadzu GC-MS QP2010SE (Shimadzu Corporation, Japan) operating in EI mode at 70 Ev equipped with an National Institute of Standards and Technology (NIST) spectral database was used for the identification of the chemical compounds present in the extracts. A BPX5 capillary column $30 \mathrm{~m} \times 0.25 \mathrm{~mm}$ (internal diameter [id]) and helium gas with a flow rate of $1.2 \mathrm{~mL} / \mathrm{min}$ were used as the carrier gas, whilst the oven temperature and the mass range were set at $60{ }^{\circ} \mathrm{C}$ and $40-400$ mass/charge ratio (m/z), respectively. Various compounds were identified by their retention time and the NIST library search (Madivoli et al. 2018).

\section{Data analysis}

The data obtained in this study were evaluated by using statistical software and are represented as mean \pm standard deviation.

\section{Ethical consideration}

Ethical clearance was not required for the study.

\section{Results}

The results of proximate analysis of L. trifolia are depicted in Table 1.

Proximate composition is the term usually used in the field of feed/food to mean the components of moisture, crude protein, ether extract, crude fibre, crude ash and nitrogenfree extracts expressed as the content (\%) in the sample. From the results obtained (Table 1), total carbohydrates were found to be higher in L. trifolia stalks (as $81.64 \pm 0.02 \%$ ) compared with leaves $(72.85 \pm 0.01 \%)$ and roots $(60.68 \pm 0.08 \%)$. Crude fibre, on the other hand, was found to be higher in L. trifolia leaves $(53.35 \pm 0.11 \%)$ compared with its stalks $(44.61 \pm$ $0.02 \%)$ and roots $(20.99 \pm 0.30 \%)$. Protein content was found to be higher in roots followed by leaves and stalks, and the fat content was found to be higher in roots compared with stalks and leaves. The micro- and macronutrient contents of L. trifolia are depicted in Table 2.

From the results obtained, it can be observed that L. trifolia had high concentration of both micro- and macronutrient contents, but the concentration varied depending on the plant part. The concentration of all nutrients was observed to be higher in the leaves compared with the stalks and roots. When compared with the stalks, the roots were found to have higher concentrations of all nutrients except sodium and zinc.

The results for quantification of total phenolic and total flavonoid contents of L. trifolia extracts are shown in Table 3.

From the results, it can be observed that L. trifolia has a high concentration of both total phenolic and flavonoid contents. The leaves of $L$. trifolia recorded the highest content of both total phenolic and total flavonoid contents of

TABLE 1: Proximate composition of Lantana trifolia leaves, stalks and roots.

\begin{tabular}{lccc}
\hline Parameters & \multicolumn{3}{c}{ Average content (\%) } \\
\cline { 2 - 4 } & Leaves & Stalks & Roots \\
\hline Moisture content & $5.60 \pm 0.01$ & $7.95 \pm 0.00$ & $8.36 \pm 0.05$ \\
Ash content & $15.35 \pm 0.01$ & $4.81 \pm 0.04$ & $12.90 \pm 0.00$ \\
Nitrogen content & $0.95 \pm 0.01$ & $0.86 \pm 0.01$ & $2.62 \pm 0.00$ \\
Protein content & $5.91 \pm 0.05$ & $5.38 \pm 0.04$ & $16.40 \pm 0.03$ \\
Fat content & $0.20 \pm 0.00$ & $0.25 \pm 0.00$ & $1.71 \pm 0.01$ \\
Crude fibre & $53.35 \pm 0.11$ & $44.61 \pm 0.02$ & $20.99 \pm 0.30$ \\
Total carbohydrates & $72.85 \pm 0.01$ & $81.64 \pm 0.02$ & $60.68 \pm 0.08$ \\
\hline
\end{tabular}

TABLE 2: Micro- and macronutrient compositions of Lantana trifolia plant.

\begin{tabular}{lccc}
\hline Element & Leaves $(\mathrm{mg} / \mathrm{kg})$ & Stalks $(\mathrm{mg} / \mathrm{kg})$ & Roots $(\mathrm{mg} / \mathrm{kg})$ \\
\hline Aluminium & $7510.34 \pm 156.20$ & $366.41 \pm 10.15$ & $2561.16 \pm 41.21$ \\
Boron & $59.75 \pm 44.12$ & $34.39 \pm 1.33$ & $72.61 \pm 0.83$ \\
Calcium & $8860.75 \pm 565.27$ & $7290.66 \pm 154.77$ & $14412.07 \pm 154.97$ \\
Cobalt & $3.65 \pm 0.26$ & $0.00 \pm 0.00$ & $0.00 \pm 0.00$ \\
Copper & $22.625 \pm 0.10$ & $13.74 \pm 0.24$ & $22.63 \pm 1.41$ \\
Chromium & $9.21 \pm 0.27$ & $1.54 \pm 0.45$ & $3.49 \pm 0.26$ \\
Iron & $11003.10 \pm 143.24$ & $427.83 \pm 11.35$ & $5602.55 \pm 26.85$ \\
Magnesium & $1520.25 \pm 26.85$ & $1179.37 \pm 13.97$ & $2274.31 \pm 12.88$ \\
Phosphorus & $1728.89 \pm 99.04$ & $1132.55 \pm 36.12$ & $3247.05 \pm 8.11$ \\
Sodium & $346.88 \pm 38.93$ & $324.56 \pm 5.01$ & $298.76 \pm 83.35$ \\
Zinc & $39.66 \pm 15.68$ & $36.33 \pm 4.24$ & $27.81 \pm 7.36$ \\
\hline
\end{tabular}


$457.17 \pm 0.12 \mathrm{mg}$ garlic equivalent (GE)/g dry weight (DW) and $109.59 \pm 4.81 \mathrm{mg} \mathrm{RE} / \mathrm{g}$ DW compared with the stalks that had total phenolic and flavonoid contents of $436.37 \pm$ $0.51 \mathrm{mg}$ GE/g DW and $106.66 \pm 7.55 \mathrm{mg} \mathrm{RE} / \mathrm{g} \mathrm{DW}$, respectively. The roots had the lowest content of both total phenols and total flavonoids at $307.17 \pm 0.65 \mathrm{mg}$ GE $/ \mathrm{g}$ DW and $95.15 \pm 0.20 \mathrm{mg}$ RE/g DW, respectively.

Figure 1 depicts the GC-MS chromatogram of L. trifolia methanolic extract, whilst the mass spectrums of some of the compounds identified are depicted in Figures 2-5.

From the GC-MS results (Table 4), L. trifolia extracts had various secondary metabolites that have been reported to

TABLE 3: Total phenolic and total flavonoid contents of Lantana trifolia extracts.

\begin{tabular}{lcc}
\hline Plant part & Total phenols $(\mathrm{mg} \mathrm{GE} / \mathrm{g} \mathrm{DW})$ & Total flavonoids $(\mathrm{mg} \mathrm{RE} / \mathrm{g} \mathrm{DW})$ \\
\hline Stalks & $436.37 \pm 0.51$ & $106.66 \pm 7.55$ \\
Leaves & $457.17 \pm 0.12$ & $109.59 \pm 4.81$ \\
Roots & $307.17 \pm 0.65$ & $95.15 \pm 0.20$ \\
\hline
\end{tabular}

GE, garlic equivalent; DW, dry weight; RE, Rutin equivalent.

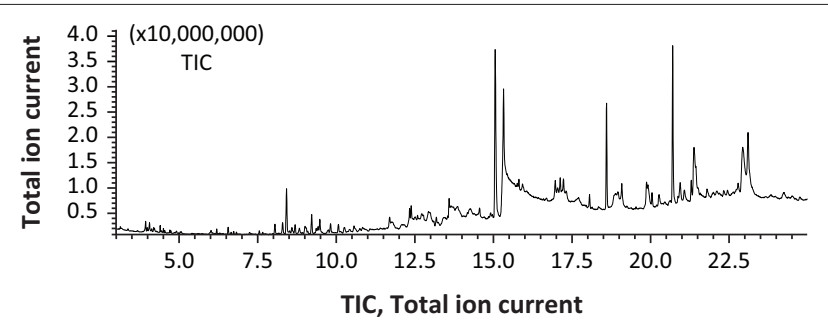

TIC, total ion current

FIGURE 1: Gas chromatography-mass spectrometry chromatogram of Lantana trifolia methanolic extracts. have medicinal value. Analyses by using GC-MS revealed the presence of nonanoic acid, 1,7-octadien-3-ol, cis-3hexenoic acid, Z-2-octen-1-ol, E-2-Decen-1-ol, 2-Nonen-1-ol, 3-cyclopropyl-7-hydroxylmethyl bicyclo[4.1.0]heptane, amongst many other compounds that have been reported to have medicinal properties.

\section{Discussion}

Wild edible plants are known to make important contributions to food baskets and livelihoods in the smallholder and subsistence farming communities of sub-Saharan Africa (Shumsky et al. 2014). As a result, protecting and promoting the sustainable use of these plants in concert with more mainstream agricultural innovation efforts have the potential to build household resilience to food insecurity (Altieri 2002). The presence of a high carbohydrate content in L. trifolia implies that it can be a good source of energy. Proteins, lipids and carbohydrates contribute to the total energy content of an organism, whilst water and ash contribute only to the mass content. Carbohydrates are found abundantly in nature, both in plants and in animals, and are the essential constituents of all living matter (Spitz et al. 2010; Thangaraj 2016; Unuofin, Otunola \& Afolayan 2017b). These micronutrients play an important role not only in the growth and development of plants but also in the development of humans; hence, they are essential and should be provided regularly through dietary intake (Shukla et al. 2018). Widespread nutritional deficiencies of $\mathrm{Fe}, \mathrm{Zn}$, iodine and vitamin A affecting human health disproportionately, especially women and young children, have been widely reported, hence the rush in food fortification which is an excellent way to improve dietary quality (Horton \& Mannar

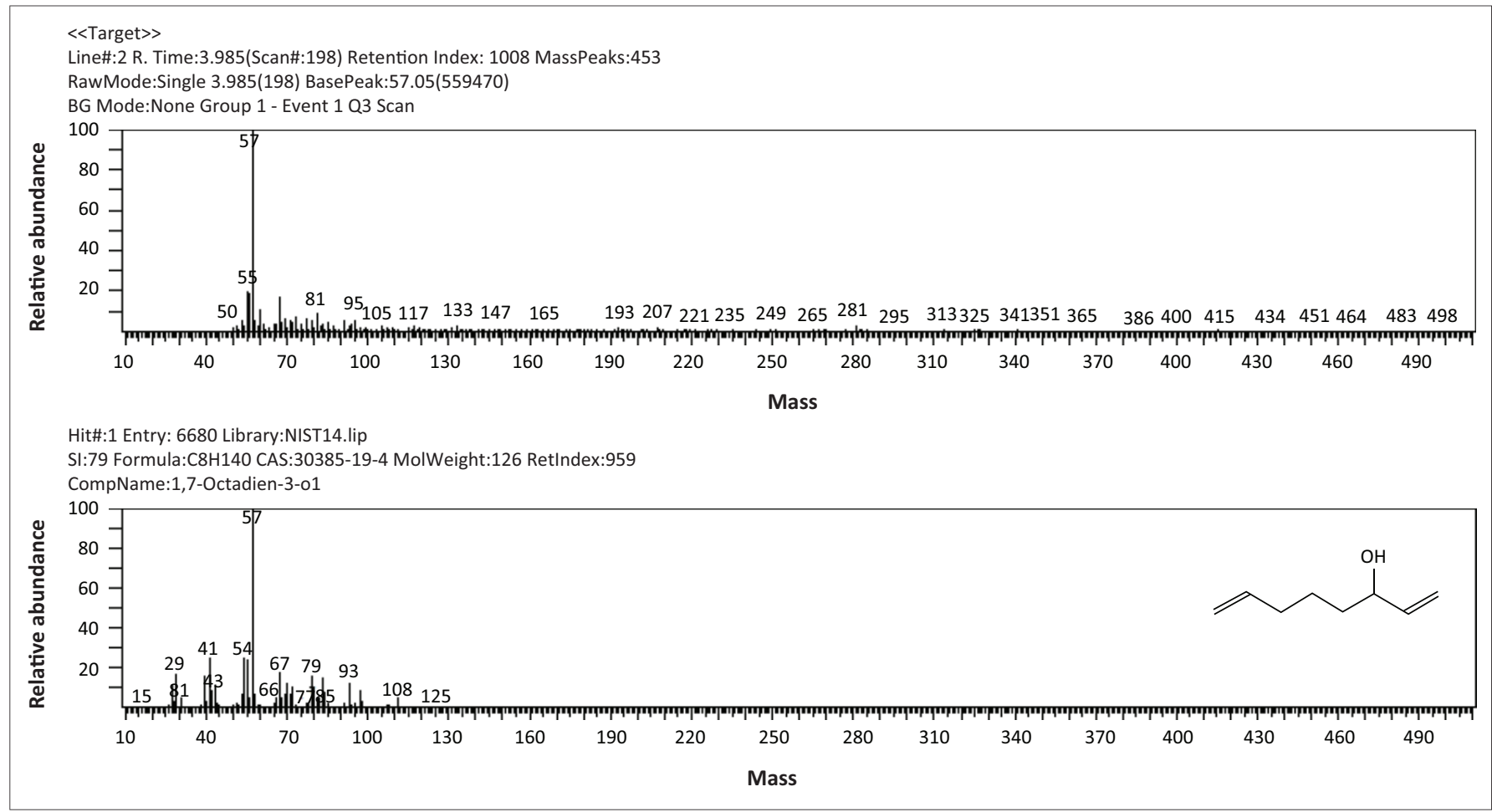

FIGURE 2: Gas chromatography-mass spectrometry spectra of 1,7-octadien-3-ol as identified with the help of an NIST spectral database library. 


\section{Library \\ <<Target $>>$}

Line\#:1 R. Time:3.935(Scan\#:188) Retention Index:1001 MassPeaks:449

RawMode:Single 3.935(188) BasePeak:60.00(605196)

BG Mode:None Group 1 - Event 1 Q3 Scan

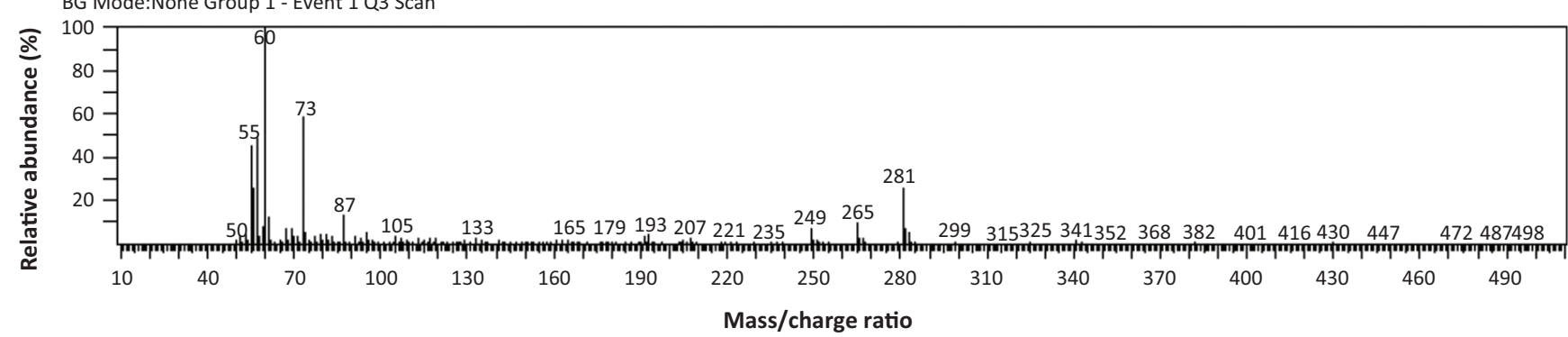

Hit\#:1 Entry:20066 Library:NIST14.lip

SI:75 Formula:C9H1802 CAS:112-05-0 MolWeight:158 RetIndex:1272

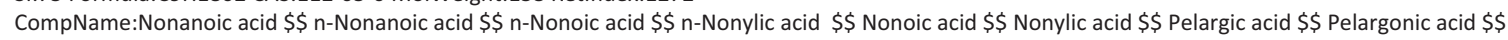

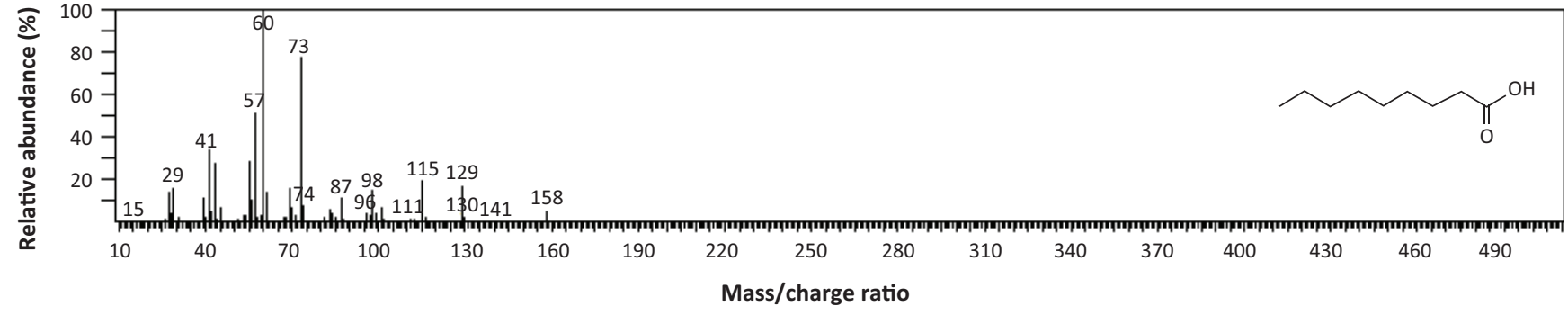

FIGURE 3: Gas chromatography-mass spectrometry spectra of n-nonanoic acid as identified with the help of NIST library.

$<$ Target $>>$

Line\#:26 R. Time:7.250(Scan\#:851) Retention Index:1381 MassPeaks:450

RawMode:Single 7.250(851) BasePeak:55.05(81921)

BG Mode:None Group 1 - Event 1 Q3 Scan

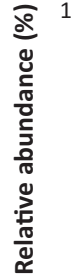

100 J 55

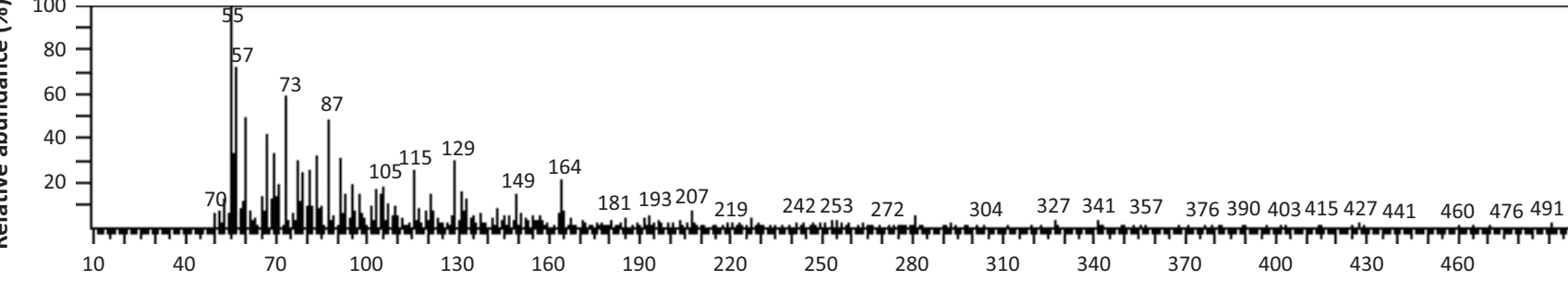

Hit\#:1 Entry:156705 Library:NIST14.lip

SI:76 Formula:C22H3202 CAS:60534-16-9 MolWeight:328 RetIndex:2413

CompName:Spiro[androst-5-ene-17,1'-cyclobutan]-2'-one, 3-hydroxy-, (3.beta., 17.beta.)-

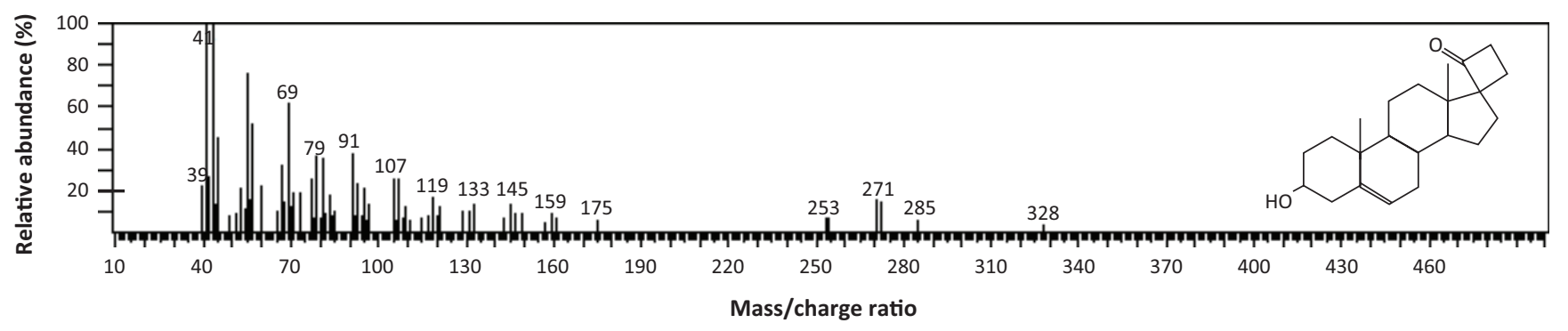

FIGURE 4: Gas chromatography-mass spectrometry spectra of spiro[androst-5-ene-17,1-cyclobutan]-2-one, (3-hydroxyl-, 3,beta,17.beta)- as identified with the help of an National Institute of Standards and Technology spectral database.

2018). Wild edible plants play vital roles in the traditional medicine, as trace elements present in these plants are also known for their preventive and curative roles in combating diseases. In developing countries such as Kenya, some of these plants are unexplored as sources of food, although they have been widely utilised as sources of folklore medicines to combat several diseases (Shaheen, Ahmad \& Haroon 2017). Even though the concentration of mineral elements present in the plant materials is considerably small compared with its total body weight and total composition, they still play an important physiological role in the metabolism of human body (Shaheen et al. 2017; White \& Brown 2010). 


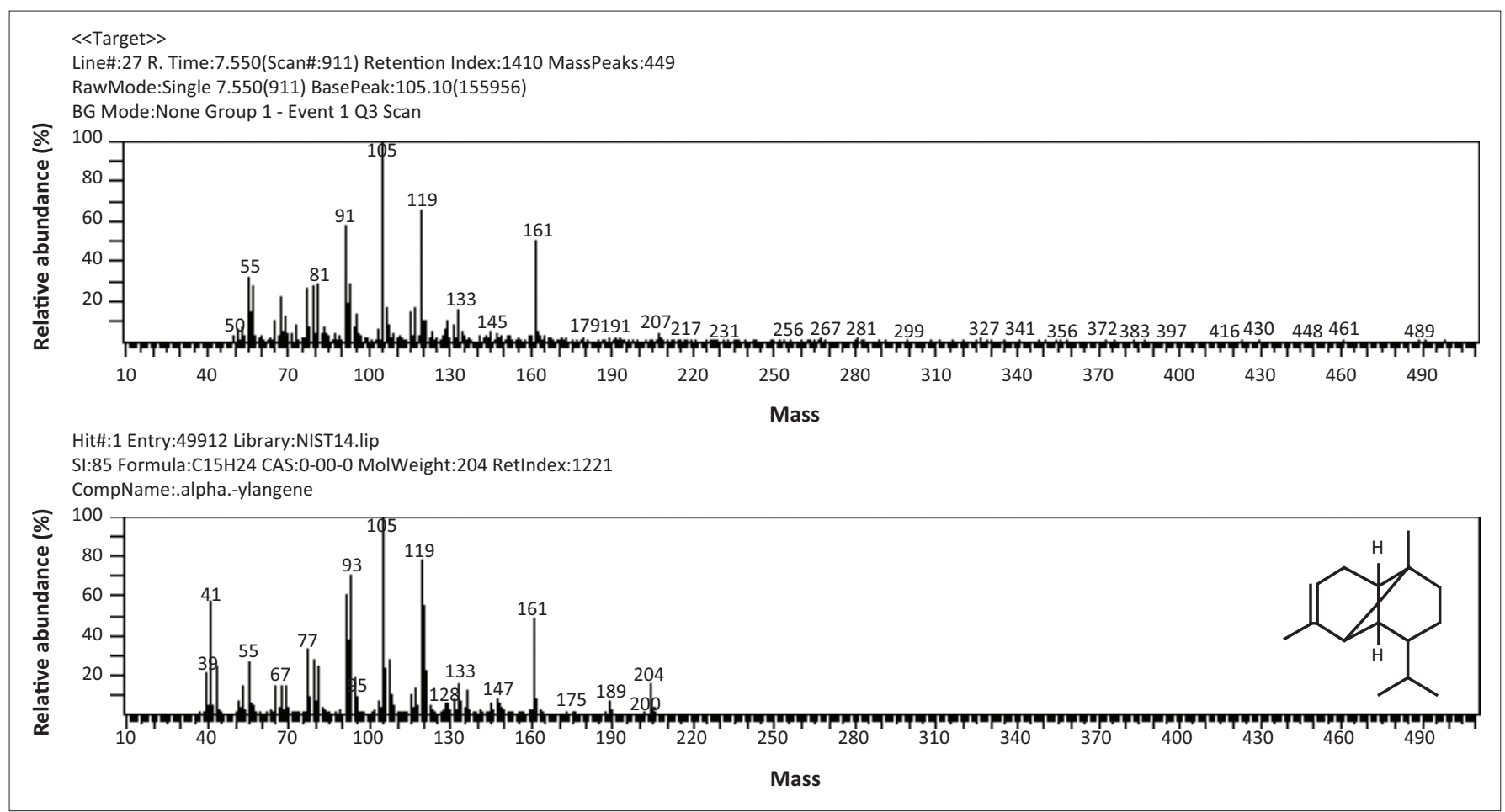

FIGURE 5: Gas chromatography-mass spectrometry spectra of alpha-ylangene as identified with the help of an National Institute of Standards and Technology spectral database.

TABLE 4: Gas chromatography-mass spectrometry profile of Lantana trifolia methanolic extracts identified with the help of National Institute of Standards and Technology gas chromatography-mass spectrometry data base.

\begin{tabular}{|c|c|c|c|c|}
\hline Number & Compound name & $\begin{array}{l}\text { Ret. } \\
\text { time }\end{array}$ & $\mathrm{m} / \mathrm{z}$ & $\begin{array}{c}\text { Retention } \\
\text { index }\end{array}$ \\
\hline 1 & Nonanoic acid & 3.94 & 60 & 1001 \\
\hline 2 & 1,7-Octadien-3-ol & 3.985 & 57 & 1008 \\
\hline 3 & cis-3-Hexenoic acid & 4.055 & 55 & 1017 \\
\hline 4 & 2-Octen-1-ol, (Z)- & 4.125 & 57 & 1026 \\
\hline 5 & 2-Decen-1-ol, (E)- & 4.19 & 57 & 1034 \\
\hline 6 & 2-Nonen-1-ol & 4.215 & 57 & 1037 \\
\hline 7 & $\begin{array}{l}\text { Bicyclo[4.1.0]heptane,-3-cyclopropyl,- } \\
\text { 7-hydroxymethyl, (cis) }\end{array}$ & 4.395 & 67 & 1061 \\
\hline 8 & $\begin{array}{l}\text { Benzaldehyde, 3-benzyloxy-2-fluoro- } \\
\text { 4-methoxy- }\end{array}$ & 4.505 & 91 & 1075 \\
\hline 9 & 2-Octen-1-ol, (E)- & 4.54 & 57 & 1080 \\
\hline 10 & 1,2:4,5:9,10-Triepoxydecane & 4.705 & 69 & 1101 \\
\hline 11 & 3-Trifluoroacetoxypentadecane & 4.74 & 69 & 1105 \\
\hline 12 & Cyclopentaneundecanoic acid & 4.91 & 57 & 1126 \\
\hline 13 & 19,19-Dimethyl-eicosa-8,11-dienoic acid & 4.985 & 57 & 1135 \\
\hline 14 & Undec-10-ynoic acid, isobutyl ester & 5.03 & 57 & 1140 \\
\hline 15 & 12,15-Octadecadiynoic acid, methyl ester & 5.07 & 57 & 1145 \\
\hline 16 & Z,Z-2,5-Pentadecadien-1-ol & 5.59 & 57 & 1208 \\
\hline 17 & $\begin{array}{l}\text { Spiro[androst-5-ene-17, } 1^{\prime} \text {-cyclobutan] } \\
\text {-2'-one, 3-hydroxy-, (3.beta.,17.beta.)- }\end{array}$ & 5.63 & 57 & 1212 \\
\hline 18 & Z,Z-2,5-Pentadecadien-1-ol & 5.71 & 57 & 1221 \\
\hline 19 & $\begin{array}{l}\text { Spiro[androst-5-ene-17,1'-cyclobutan] } \\
\text {-2'-one, 3-hydroxy-, (3.beta.,17.beta.)- }\end{array}$ & 5.745 & 57 & 1225 \\
\hline 20 & 3-Octyne, 7-methyl- & 6.015 & 67 & 1254 \\
\hline
\end{tabular}

Ret., retention time; $\mathrm{m} / \mathrm{z}$, mass/charge ratio.

Higher phenolic and flavonoid contents have been linked to a higher antioxidant activity as phenolic compounds have been reported to possess a high free radical scavenging ability (Unuofin et al. 2017). Of late several health conditions such as diabetes, high blood pressure (Tabassum \& Ahmad 2011) and high cholesterol levels (Gurbuz et al. 2018) in humans have been combated by using appropriate diets. Recent studies have reported the potential health benefits of polyphenols and their pharmacological potentials, which include but are not limited to anti-diabetic (Habtemariam \& Varghese 2014), anti-cancerogenic (Rodrigues et al. 2012), anti-ulcerogenic (Coelho et al. 2009), anti-oestrogenic (El-Halawany et al. 2007) and anti-inflammatory effects (Wang et al. 2014). Phenols such as flavonoids and terpenoids exert their antioxidant activity by mopping up free radicals and reactive oxygen species, thereby playing a major role in scavenging oxidative free radicals (Unuofin et al. 2017; Sen et al. 2010).

These compounds belong to various classes of compounds such as terpenoids, alcohols, terpenes, acids, esters, aldehydes and ketones. These bioactive compounds that are produced by plants are used to support health and fight against infections, and many of them are sold as foods or herbal medicines. Their usage has dramatically increased over the last decade because of not only their ease of access and low cost but also the belief that natural remedies have less lethal effects compared with synthetic analogues (Hadi, Mohammed \& Hameed 2016). Qualitative study of L. trifolia revealed the presence of tannins, flavonoids, sterols, triterpenes, saponins, volatile oils and anthraquinones which were identified via capillary GC-MS with the help of NIST spectral database, thus identifying 80 compounds (Sousa \& Costa 2012). The therapeutic activity of L. trifolia can be attributed to the presence of these secondary metabolites, but the greater part of their activity was because of the presence of several bioactive agents, namely alkaloids, saponins, lignans, iso-catechin, coumarins, flavonoids, tannins, flavones and isoflavones (Cabrido \& Demayo 2018; Sousa \& Costa 2012). 


\section{Conclusion}

Locally available wild plants such as L. trifolia are not only recognised for their characteristic therapeutic value, but they are also a rich source of proteins, calories, iron, zinc and a host of other micronutrients. They are also important sources of energy and are frequently used as part of the dietary food to manage the degenerative diseases and nutrient deficiencies. In addition to making significant additions to individual family food supplies, wild food plants such as L. trifolia can also contribute to household food security amongst communities. There is a need to utilise wild plants as food sources to ensure that communities have food security and, in the process, eradicate malnutrition that is prevalent in Kenya and in most areas of sub-Saharan Africa. Moreover, the large variety of secondary metabolites present in this plant ensures that various health disorders and complications are combated, and in the process the health status of undernourished population can be improved.

\section{Acknowledgements}

The authors acknowledge the support of the Department of Chemistry, Jomo Kenyatta University of Agriculture and Technology, for granting access to the facilities used in this study.

\section{Competing interests}

The authors declare that they have no financial or personal relationships that may have inappropriately influenced them in writing this article.

\section{Authors' contributions}

All authors contributed equally to the design and implementation of the research, to the analysis of the results and to the writing of the manuscript.

\section{Funding information}

The authors received no financial support for the research and authorship of this article.

\section{Data availability statement}

The authors confirm that the data supporting the findings of this study are available within the article and/or its supplementary material.

\section{Disclaimer}

The views and opinions expressed in this article are those of the authors and do not reflect the official policy or position of any affiliated agency of the authors.

\section{References}

Altieri, M.A., 2002, 'Agroecology: The science of natural resource management for poor farmers in marginal environments', Agriculture, Ecosystems \& Environment 93(1-3), 1-24. https://doi.org/10.1016/S0167-8809(02)00085-3
Bharucha, Z. \& Pretty, J., 2010, 'The roles and values of wild foods in agricultural systems', Philosophical Transactions of the Royal Society of London B: Biological Sciences 365(1554), 2913-2926. https://doi.org/10.1098/rstb.2010.0123

Cabrido, C. \& Demayo, C.G., 2018, 'Antimicrobial and cellular metabolic effects of the ethanolic extract of the dallas red variety of lantana camara', Pharmacophore 9(1), 10-16

Coelho, R.G., Gonzalez, F.G., Sannomiya, M., Di Stasi, L.C. \& Vilegas, W., 2009, 'Gastric anti-ulcer activity of leaf fractions obtained of polar extract from Wilbrandia ebracteata in mice', Natural Product Research 23(1), 51-59. https://doi. ebracteata in mice', Natural Prod
org/10.1080/14786410701782544

Dzialo, M., Mierziak, J., Korzun, U., Preisner, M., Szopa, J. \& Kulma, A., 2016, 'The potential of plant phenolics in prevention and therapy of skin disorders', International Journal of Molecular Sciences 17(2), 160. https://doi.org/10.3390/ ijms 17020160

El-Halawany, A.M., Chung, M., Nakamura, N., Zhuxin, M. \& Nishihara, T. \& Hattori, M., 2007, 'Estrogenic and anti-estrogenic activities of Cassia tora phenolic constituents', Chemical and Pharmaceutical Bulletin 55(10), 1476-1482. https:// doi.org/10.1248/cpb.55.1476

Estefan, G., Sommer, R. \& Ryan, J., 2013, Methods of soil, plant, and water analysis: A manual for the west, Asia and North Africa region, 3rd edn., ICARDA, Beirut.

Gurbuz, N., Uluişik, S., Frary, A., Frary, A. \& Doğanlar, S., 2018, 'Health benefits and bioactive compounds of eggplant', Food Chemistry 268(1), 602-610. https://doi. org/10.1016/j.foodchem.2018.06.093

Habtemariam, S. \& Varghese, G.K., 2014, 'The antidiabetic therapeutic potential of dietary polyphenols', Current Pharmaceutical Biotechnology 15(4), 391-400. https://doi.org/10.2174/1389201015666140617104643

Hadi, M.Y., Mohammed, G.J. \& Hameed, I.H., 2016, 'Analysis of bioactive chemical compounds of Nigella sativa using gas chromatography-mass spectrometry', Journal of Pharmacognosy and Phytotherapy 8(2), 8-12. https://doi.org/10.5897/ JPP2015.0364

Horton, S. \& Mannar, M.V., 2018, Economics of food fortification, Regional Land Management Unit, Nairobi.

Hossain, M.A., AL-Raqmi, K.A.S., AL-Mijizy, Z.H., Weli, A.M. \& Al-Riyami, Q., 2013 'Study of total phenol, flavonoids contents and phytochemical screening of various leaves crude extracts of locally grown Thymus vulgaris', Asian Pacific Journal of Tropical Biomedicine 3(9), 705-710. https://doi.org/10.1016/S22211691(13)60142-2

Lefahal, M., Zaabat, N., Ayad, R., Makhloufi, E., Djarri, L., Benahmed, M. et al., 2018, 'In vitro assessment of total phenolic and flavonoid contents, antioxidant and photoprotective activities of crude methanolic extract of aerial parts of Capnophyllum peregrinum (L.) Lange (Apiaceae) growing in Algeria', Medicines 5(2), 26. https://doi.org/10.3390/medicines5020026

Madivoli, E.S., Maina, E.G., Kairigo, P.K., Murigi, M., Ogilo, J., Nyang'au, J. et al., 2018 In vitro antioxidant and antimicrobial activity of Prunus africana (Hook. f.) Kalkman (barks extracts) and Harrisonia abyssinica Oliv. extracts (barks extracts): A comparative study', Journal of Medicinal Plants for Economic Development 2(1), 1-9. https://doi.org/10.4102/jomped.v2i1.39

Maina, E.G., Madivoli, E.S., Ouma, J.A., Ogilo, J., Kenya, J.M., 2019, 'Evaluation of nutritional value of Asystasia mysorensis and Sesamum angustifolia and their potential contribution to human health', Food Science and Nutrition 7(6), 1-10. https://doi.org/10.1002/fsn3.1064

Olaniyi, M.B., Lawal, I.O. \& Olaniyi, A.A., 2018, 'Proximate, phytochemical screening and mineral analysis of Crescentia cujete L leaves', Journal of Medicinal Plants for Economic Development 2(1), 7. https://doi.org/10.4102/jomped.v2i1.28

Peduzzi, P. \& Harding Rohr Reis, R., 2012, 'The end to cheap oil: A threat to food security and an incentive to reduce fossil fuels in agriculture, Environmental Development 3(1), 157-165. https://doi.org/10.1016/j.envdev.2012.05.008

Rodrigues, S., Calhelha, R.C., Barreira, J.C.M., Dueñas, M., Carvalho, A.M., Abreu, R.M.V. et al., 2012, 'Crataegus monogyna buds and fruits phenolic extracts: Growth inhibitory activity on human tumor cell lines and chemical characterization by HPLC-DAD-ESI/MS', Food Research International 49(1), 516-523. https://doi. org/10.1016/j.foodres.2012.07.046

Ruffo, C.K., Birnie, A. \& Tengnas, B., 2002, Edible wild plants of Tanzania, Regional Land Management Unit, Nairobi.

Scheller, J., Chalaris, A., Schmidt-Arras, D. \& Rose-John, S., 2011, 'The pro- and antiinflammatory properties of the cytokine interleukin-6', Biochimica et Biophysica
Acta (BBA)-Molecular Cell Research 1813(5), 878-888. https://doi.org/10.1016/j. Acta (BBA)-Molecular
bbamcr.2011.01.034

Schmidhuber, J. \& Tubiello, F.N., 2007, 'Global food security under climate change', Proceedings of the National Academy of Science 104(50), 19703-19708. https:// doi.org/10.1073/pnas.0701976104

Sen, S., Chakraborty, R., Sridhar, C., Reddy, Y.S.R. \& Debnath, B., 2010, 'Free radicals, antioxidants, diseases and phytomedicines: Current status and future prospect', International Journal of Pharmaceutical Sciences Review and Research 3(1), 91-100.

Shaheen, S., Ahmad, M. \& Haroon, N., 2017, Edible wild plants: An alternative approach to food security, Springer International Publishing, Berlin.

Shaikh, R.U., Pund, M.M. \& Gacche, R.N., 2016, 'Evaluation of anti-inflammatory activity of selected medicinal plants used in Indian traditional medication system in vitro as well as in vivo, Journal of Traditional and Complementary Medicine 6(4), 355-361. https://doi.org/10.1016/j.jtcme.2015.07.001

Shukla, A.K., Behera, S.K., Pakhre, A. \& Chaudhari, S.K., 2018, 'Micronutrients in soils, plants, animals and humans', Indian Journal of Fertilisers 14(3), 30-54.

Shumsky, S.A., Hickey, G.M., Pelletier, B. \& Johns, T., 2014, 'Understanding the contribution of wild edible plants to rural social-ecological resilience in semi-arid Kenya', Ecology and Society 19(4), 34. http://doi.org/10.5751/ES-06924-190434 
Silva, G.N., Martins, F.R., Matheus, M.E., Leitão, S.G. \& Fernandes, P.D., 2005, 'Investigation of anti-inflammatory and antinociceptive activities of Lantana
trifolia', Journal of Ethnopharmacology 100(3), 254-259. https://doi.org/10.1016/j. jep.2005.02.040

Sousa, E.O. \& Costa, J.G., 2012, 'Genus Lantana: Chemical aspects and biologica activities', Revista Brasileira de Farmacognosia 22(5), 1115-1180. https://doi org/10.1590/s0102-695X2012005000058

Spitz, J., Mouroq, E., Schoen, V. \& Ridoux, V., 2010, 'Proximate composition and energy content of forage species from the Bay of Biscay: High-or low-quality food?', ICES Journal of Marine Science 67(5), 909-915. https://doi.org/10.1093/ icesjms/fsq008

Tabassum, N. \& Ahmad, F., 2011, 'Role of natural herbs in the treatment of hypertension', Pharmacognosy Reviews 5(9), 30. https://doi.org/10.4103/09737847.79097

Thangaraj, P., 2016, Pharmacological assays of plant based natural products, Springer Geneva.

Tumushabe, J.T., 2018, 'Climate change, food security and sustainable development in Africa', in S.O. Oloruntoba and T. Falola (eds.), The Palgrave handbook of African politics, governance and development, pp. 853-868, Palgrave Macmillan, New York, NY.
Unuofin, J.O., Otunola, G.A. \& Afolayan, A.J., 2017a, 'Nutritional evaluation of Kedrostis africana (L.) Cogn: An edible wild plant of South Africa', Asian Pacific Journal of Tropical Biomedicine 7(5), 443-449. https://doi.org/10.1016/j.apjtb.2017.01.016

Unuofin, J.O., Otunola, G.A. \& Afolayan, A.J., 2017b, 'Phytochemical screening and in vitro evaluation of antioxidant and antimicrobial activities of Kedrostis africana (L.) Cogn', Asian Pacific Journal of Tropical Biomedicine 7(10), 901-908. https:// doi.org/10.1016/j.apjtb.2017.09.008

USAID, 2018, Kenya: Nutrition profile, USAID, Nairobi.

Wang, Q.S., Yang, L., Cui, W-Y., Chen, L. \& Jiang, Y-H., 2014a, 'Anti-inflammatory and antinociceptive activities of methanol extract from aerial part of Phlomis younghusbandil Mukerjee', PLoS One 9(3), e89149. https://doi.org/10.1371/journal.pone.0089149

Wang, S., Moustaid-Moussa, N., Chen, L., Mo, H., Shastri, A., Su, R. et al., 2014b, 'Novel insights of dietary polyphenols and obesity', The Journal of Nutritional Biochemistry 25(1), 1-18. https://doi.org/10.1016/j.jnutbio.2013.09.001

Waweru, W.R., Osuwat, L.O. \& Wambugu, F.K., 2017, 'Phytochemical analysis of selected indigenous medicinal plants used in Rwanda', Journal of Pharmacognosy and Phytochemistry 1(1), 322-324.

White, P.J. \& Brown, P.H., 2010, 'Plant nutrition for sustainable development and global health', Annals of Botany 105(7), 1073-1080. https://doi.org/10.1093/aob/mcq085

Witte, M.B. \& Barbul, A., 2002, 'Role of nitric oxide in wound repair', The American Journal of Surgery 183(4), 406-412. https://doi.org/10.1016/S0002-9610(02)00815-2 